\title{
Thermal Tolerances of Three Tramp Ant Species (Hymenoptera: Formicidae)
}

by

\author{
Daniel Russ Solis \& Odair Correa Bueno
}

\begin{abstract}
Tramp ant species present a set of adaptations to their urban habitats, and there is a paucity of knowledge about how they interact with abiotic factors, like temperature. Temperature is well known to interfere with insect activity. The present study evaluated the temperature tolerance of three important tramp ant species: Monomorium floricola (Jerdon), Monomorium pharaonis (Linnaeus) and Tetramorium bicarinatum (Nylander). Tested temperatures were $0,2,4,6,8,10,12,14,16,18,20,25,30,32,34,36,38,40,42,44$, 46,48 and $50^{\circ} \mathrm{C}$. Ten repetitions with 20 workers each were done with each temperature and analyzed species. The number of dead workers was recorded every hour over a total of 8 hours. All procedures were done using thermal incubators at relative humidity within 50-95\%. Workers of $M$. pharaonis proved more tolerant to high temperatures $\left(30-50^{\circ} \mathrm{C}\right)$ than workers of $M$. floricola and T. bicarinatum. The higher the temperatures tested, greater was the recorded ant mortality, with temperature $50^{\circ} \mathrm{C}$ being fatal to all species after $1 \mathrm{~h}$ of exposition. The least tolerant species to temperatures below $20^{\circ} \mathrm{C}$ was $T$. bicarinatum. Low temperatures tested were not fatal to any of the tested species.

Key words: Myrmicinae, Monomorium floricola, Monomorium pharaonis, Tetramorium bicarinatum.
\end{abstract}

\section{INTRODUCTION}

Both biotic and abiotic factors exert great influence over the functionality of organisms. Changes in these factors can be recurrent or intermittent, predictable or unpredictable, and each species differ in its ability to handle and adapt to a change of conditions (Linksvayer \& Janssen 2008). According with the same authors, examples of abiotic factors would include range of

Centro de Estudos de Insetos Sociais, Instituto de Biociências, Universidade Estadual Paulista "Júlio de Mesquita Filho", UNESP, Rio Claro, São Paulo, Brazil; e-mail: entomo75@yahoo.com 
temperature and humidity, fires, droughts, hurricanes and climate changes. Temperature is an important factor driving insect activity; the body temperature of insects reflect surrounding environmental conditions, and most of their internal heat is metabolically produced, particularly by wing muscles (Chapman 1998).

The urban ant fauna presents considerable medical and economic importance, as many species are pests of domiciliary, industrial, and commercial establishments, including some which can cause relevant structural damage; many ant species are serious pests of crops and natural habitats, and some are important mechanical vectors of pathogenic microorganisms in hospital areas, and can cause severe allergic reactions (Vega \& Rust 2001; Campos-Farinha et al. 2002; Klotz et al. 2008). Among urban ants, there are those species baptized 'tramp species', which feature a set of advantageous characteristics that enabled them to adapt to humanized environments, as described in Passera (1994). Tramp ant species typically have a global geographical distribution, being only absent in the coldest world parts (e.g., Antarctica) (Wetterer 2008, 2009a, 2009b, 2009c, 2009d, 2010a, 2010b).

Based on the classification of ants into functional groups proposed by Andersen (2000), it can be seen that the most common tramp ant species would include representative species from dominant Dolichoderinae (e.g., Linepithema), Opportunists (e.g., Tetramorium and Paratrechina) and generalized Myrmicinae (e.g., Monomorium and Pheidole). These functional groups vary in the way they respond to environmental stress and disturbances: generalized Myrmicinae are better adapted to hot climates and shaded areas, while being only moderately sensitive to low temperature; Opportunistic species are well adapted to cool, shaded, and open, warm habitats (Andersen 1995).

In spite of the importance of urban ants, little is known about their adaptability to abiotic factors at species level. For instance, a recent study with Atta sexdens (Linnaeus) (Angilletta et al. 2007) compared the temperature tolerance of workers from urban and rural regions, and found that workers from colonies in urban environments can tolerate higher temperatures $\left(42^{\circ} \mathrm{C}\right)$ for a longer time period than workers deriving from colonies in the countryside. However, the authors could not determine whether the differences in thermal tolerance derived of some genetic component or was the result of a more flexible response to the environmental conditions. 
The present study aimed at assessing the thermal tolerance of three tramp ant species: Monomorium floricola (Jerdon), Monomorium pharaonis (Linnaeus), and Tetramorium bicarinatum (Nylander). We expect the finds to have applicable implications to managing these pest species in the urban environment, as knowledge about such basic biology parameters of pest species can elucidate how they adapted to the urban environment.

\section{MATERIAL AND METHODS}

\section{Maintenance of the ant colonies in the laboratory}

Laboratory colonies of the ants $M$. floricola, M.pharaonis, and T. bicarinatum were held in a climatized room with controlled temperature $\left(23-27^{\circ} \mathrm{C}\right)$ and humidity (50-80\%). The colonies were brought up inside wooden boxes (10.5 $\mathrm{cm} \times 8.5 \mathrm{~cm} \times 1.0 \mathrm{~cm})$, or test tubes $(25.0 \mathrm{~cm} \times 2.5 \mathrm{~cm})$, the tubes containing a piece of cotton soaked in water at the distal end and were lined with red cellophane. Ants were fed with insects, larvae of Tenebrio molitor (Linnaeus) (Coleoptera: Tenebrionidae) and Zophobassp. (Coleoptera: Tenebrionidae), adults of Gryllus sp. (Orthoptera: Gryllidae), and sugary liquids (water solution of honey and inverted sucrose), and pieces of sausage and sardine. Food items were presented three times a week, tap water was offered 'ad libitum'.

\section{Assembly and analysis of the experiment}

Randomly-picked workers from several colonies were exposed to the following temperatures: $0,2,4,6,8,10,12,14,16,18,20,25,30,32,34,36,38$, $40,42,44,46,48$ and $50^{\circ} \mathrm{C}$. Ten repetitions with 20 workers each were done with each temperature and analyzed species. These experiments were made inside a thermal incubator (Eletrolab, Model EL 101/3) containing plastic trays with water to keep interior relative humidity within $50-95 \%$; this being the range considered adequate for rearing these ants in the laboratory, as previously mentioned. Temperature variation inside the incubator was set to a minimum of $\pm 0.5^{\circ} \mathrm{C}$. In all cases, ant workers were kept in test tubes $(25 \mathrm{~cm}$ $x 2.5 \mathrm{~cm}$ ) closed with perforated tissue as a screen. With the only exception of the temperature $25^{\circ} \mathrm{C}$, the tested workers were acclimatized to the exposure temperature tests: they were brought from the rearing room $\left(23-27^{\circ} \mathrm{C}\right)$ to a thermal incubator at $25^{\circ} \mathrm{C}$, and the temperature was slowly adjusted about $0.5^{\circ} \mathrm{C} / \mathrm{min}$ to the experiment temperature. 
The number of dead workers was recorded every hour over a total of 8 hours. According with Hebling-Beraldo (1978), ants are immobilized at lower temperatures due to some cold narcosis, thus when dealing with temperatures below $8^{\circ} \mathrm{C}$ we waited for $30 \mathrm{~min}$ at room temperature until living ants recovered at ambient temperature $\left(18-21^{\circ} \mathrm{C}\right)$.

\section{Statistical analysis}

Resulting percentage of surviving workers from each temperature were transformed by arcsine to yield normal distribution. Transformed data were then submitted to analysis of variance (One-way ANOVA) followed by Dunnett's test, in order to check from which temperature mortality of workers became significant over the analyzed time periods tested. Control temperature set for Dunnett's test was $25^{\circ} \mathrm{C}$. Moreover, we calculated $\mathrm{LT}_{50}$ (lethal temperature for $50 \%$ of workers) and $\mathrm{TL}_{90}$ (lethal temperature for $90 \%$ of workers) for each species and period of exposure using Probit analysis. Obtained lethal temperature values were subjected to analysis of variance (Two-way ANOVA) followed by Tukey's test, comparing among different species and periods of exposure.

\section{RESULTS}

From analyzing the results of the 23 tested temperatures, it can be seen that total mortality was shared by the three species at the temperature of $50^{\circ} \mathrm{C}$ upon the first hour of exposure. For the other exposure periods at temperatures over $25^{\circ} \mathrm{C}$, complete mortality is shown in Fig. 2. However at temperatures below $25^{\circ} \mathrm{C}$, total mortality never occurred (Fig. 1).

From analyzing Tables 1,2, and 3, it can be observed that from temperatures above $25^{\circ} \mathrm{C}$ at longer periods of exposure there is a decrease in the temperature value at which worker mortality becomes significant, demonstrating how workers are less tolerant to high temperatures at longer periods of exposure. Most tolerant species to high temperatures was $M$. pharaonis, with the other two presenting the same amount of tolerance.

From analyzing Table 1, which presents results for temperatures below $25^{\circ} \mathrm{C}$, it can be seen that only $T$. bicarinatum exhibited significant mortality at the longer periods of exposure of 6,7, and 8 hours. However, mortality at these temperatures with $M$. floricola and $M$. pharaonis was not significant, 

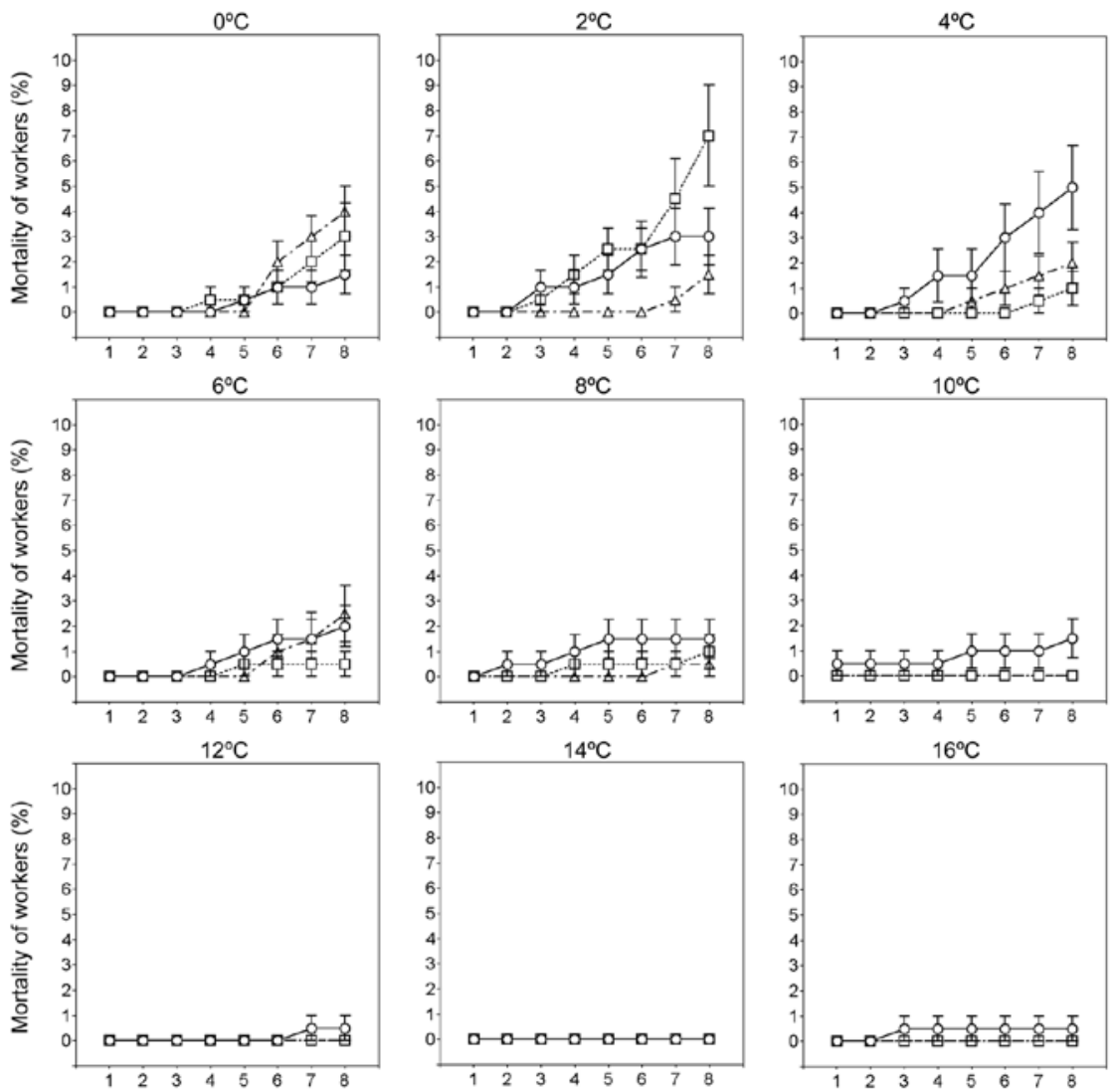

$14^{\circ} \mathrm{C}$
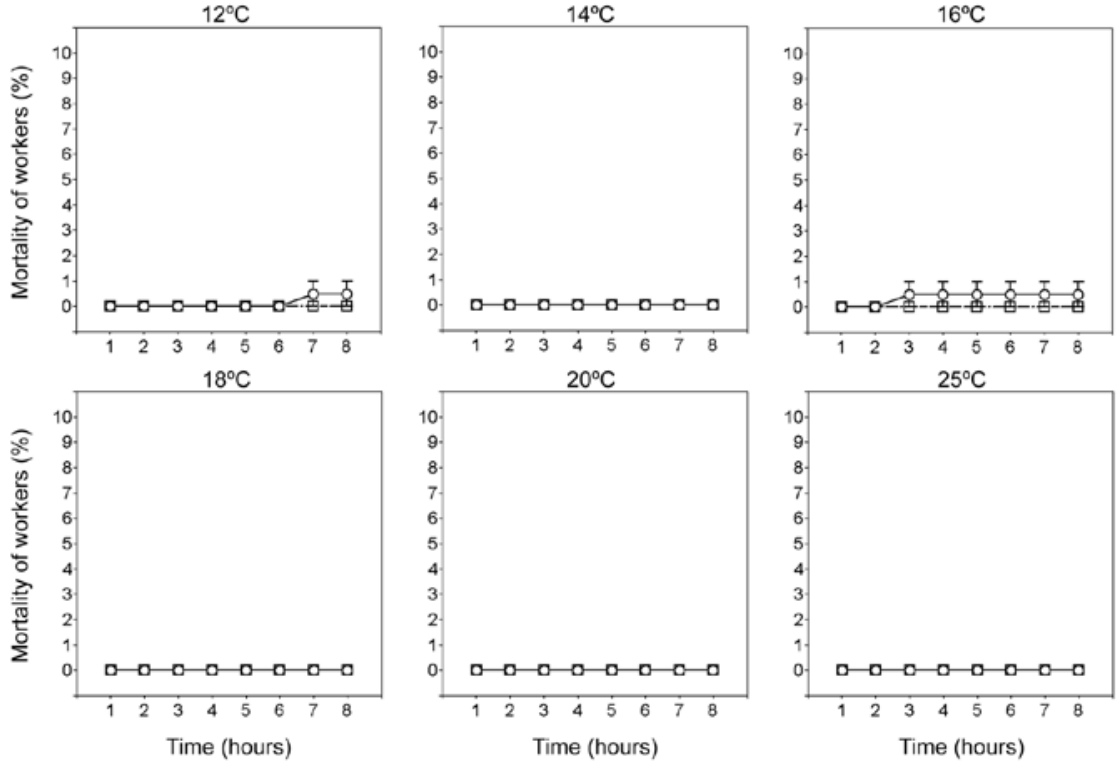

Fig. 1. Worker mortality of the tramp ant species Monomorium floricola (०), Monomorium pharaonis $(\square)$, and Tetramorium bicarinatum $(\Delta)$ when exposed to different temperatures below $25^{\circ} \mathrm{C}$ over eight hours of exposure. Error bars display standard error of the mean. 

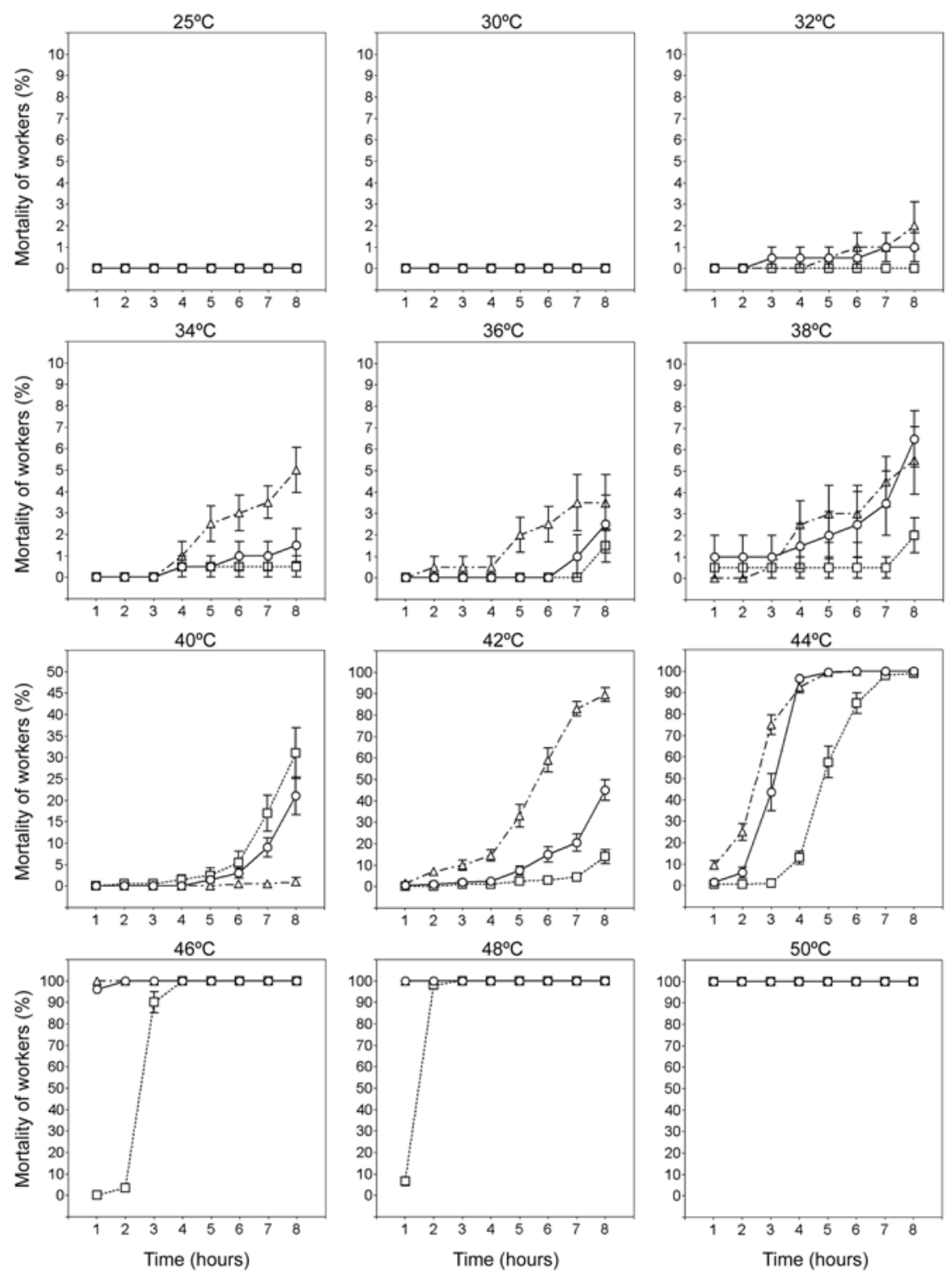

Fig. 2. Worker mortality of the tramp ant species Monomorium floricola (०), Monomorium pharaonis $(\square)$, and Tetramorium bicarinatum $(\Delta)$ when exposed to different temperatures above $25^{\circ} \mathrm{C}$ over eight hours of exposure. Error bars display standard error of the mean. 
Table 1. Temperatures from which worker mortality in three tramp ant species was significant when exposed to different experimental temperatures, according with Dunnett's test $(\mathrm{p}<0.01)$ employing $25^{\circ} \mathrm{C}$ as control temperature.

\begin{tabular}{lccccccccc}
\hline & \multicolumn{7}{c}{ Time $(\mathrm{h}) /$ Temperature $\left({ }^{\circ} \mathrm{C}\right)$} & \\
Species & 1 & 2 & 3 & 4 & 5 & 6 & 7 & 8 \\
\hline Monomorium floricola & 46 & 44 & 44 & 44 & 42 & 42 & 40 & 38 \\
Monomorium pharaonis & 48 & 46 & 46 & 44 & 44 & 44 & 40 & 40 \\
Tetramorium bicarinatum & 44 & 42 & 42 & 42 & 42 & $0 ; 42$ & $0 ; 42$ & $0 ; 42$ \\
\hline \hline
\end{tabular}

Table 2. $\mathrm{LT}_{50}$ (Lethal Temperature to $50 \%$ of sample) obtained for the tramp ants species over eight hours of continuous exposition to different temperatures above $25^{\circ} \mathrm{C}$.

\begin{tabular}{|c|c|c|c|c|c|c|c|c|}
\hline \multirow{2}{*}{ Species $^{1}$} & \multicolumn{8}{|c|}{ Time $(\mathrm{h}) /$ Temperature $\left({ }^{\circ} \mathrm{C}\right)^{2}$} \\
\hline & $1^{\mathrm{a}}$ & $2^{\mathrm{ac}}$ & $3^{\mathrm{acd}}$ & $4^{\mathrm{bc}}$ & $5^{\text {bd }}$ & $6^{\mathrm{bd}}$ & $7^{\text {bd }}$ & $8^{\text {bd }}$ \\
\hline Monomorium floricola ${ }^{\mathrm{a}}$ & 45 & 44.8 & 44.1 & 43 & 42.7 & 42.5 & 42.3 & 41.5 \\
\hline Monomorium pharaonis ${ }^{\mathrm{b}}$ & 48.8 & 46.9 & 45.2 & 44.6 & 43.7 & 43.1 & 42.7 & 42 \\
\hline Tetramorium bicarinatum ${ }^{\text {a }}$ & 44.6 & 44.3 & 43.3 & 42.8 & 42.2 & 41.6 & 41.1 & 40.9 \\
\hline
\end{tabular}

Notes. ${ }^{1}$ Figures on the same column followed by same letter did not differ by Tukey's test $(\mathrm{p}<0.01) .{ }^{2}$ Figures on the same line followed by same letter did not differ by Tukey's test $(\mathrm{p}<0.01)$.

Table 3. $\mathrm{LT}_{90}$ (Lethal Temperature to $90 \%$ of sample) obtained for the tramp ants species over eight hours of continuous exposition to different temperatures above $25^{\circ} \mathrm{C}$.

\begin{tabular}{|c|c|c|c|c|c|c|c|c|}
\hline \multirow{2}{*}{ Species $^{1}$} & \multicolumn{8}{|c|}{ Time $(\mathrm{h}) /$ Temperature $\left({ }^{\circ} \mathrm{C}\right)^{2}$} \\
\hline & $1^{\mathrm{a}}$ & $2^{\mathrm{ac}}$ & $3^{\mathrm{ac}}$ & $4^{\mathrm{ac}}$ & $5^{\mathrm{ac}}$ & $6^{\mathrm{bc}}$ & $7^{\mathrm{bc}}$ & $8^{\mathrm{bc}}$ \\
\hline Monomorium floricola $^{\text {a }}$ & 45.9 & 45.6 & 45.4 & 44 & 44 & 44 & 44.3 & 44 \\
\hline Monomorium pharaonis ${ }^{\mathrm{b}}$ & 49.6 & 47.8 & 46.1 & 45.8 & 45.2 & 44.5 & 44.2 & 44.5 \\
\hline Tetramorium bicarinatum ${ }^{\text {a }}$ & 45.3 & 45.7 & 44.7 & 44.3 & 44.2 & 43.7 & 43.2 & 43.2 \\
\hline
\end{tabular}

Notes. ${ }^{1}$ Figures on the same column followed by same letter did not differ by Tukey's test $(\mathrm{p}<0.01) .{ }^{2}$ Figures on the same line followed by same letter did not differ by Tukey's test $(\mathrm{p}<0.01)$.

suggesting that these species are more tolerant to lower temperatures than T. bicarinatum.

\section{DISCUSSION}

Hebling-Beraldo (1978) determined the $\mathrm{LT}_{50}$ over six hours of exposure of the Brazilian ant's $A$. sexdens and Atta laevigata (Smith), and found their respective tolerance limits to be $2.8^{\circ} \mathrm{C}$ and $36.3^{\circ} \mathrm{C}$, and $1.5^{\circ} \mathrm{C}$ and $37.5^{\circ} \mathrm{C}$. From comparing their obtained tolerance limits with our results, it becomes clear that our tested species have a broader temperature tolerance. We think this might be correlated with the fact that they are exotic invasive species, which are expected to be more tolerant to altered abiotic conditions. As an 
example of a Brazilian ant invasive to other countries, Xu et al. (2009) obtained the $\mathrm{LT}_{50}$ for the fire ant Solenopsis invicta (Buren) of $43.5^{\circ} \mathrm{C}$ after one hour of exposure, which is still lower than the herein recorded with other three species. Tramp ant species have worldwide distribution and are typical of humanized areas, thus probably display physiological and behavioral adaptations that allow their survival in stressful environments wherein the native species cannot thrive (Passera 1994). For instance, some species do not build their nests in an organized fashion into the soil (herein including tramp ant species), and living under rocks and fallen branches, there are physiologically less vulnerable to lower humidity or higher temperatures (Hölldobler \& Wilson 1990).

However, Linksvayer \& Janssen (2008) stated opportunistic ant species are more tolerant to stressful and disturbed environments, but cannot out compete species adapted to extreme temperatures. For instance, Walters \& Mackay (2004) compared heat tolerance of Linepithema humile (Mayr) (an invasive species) in Australia in comparison with two native species: Iridomyrmex rufoniger (Lown) and Rhytidoponera convex (Mayr). These authors found all $L$. humile died after one hour of exposure to $50^{\circ} \mathrm{C}$, while others were more tolerant: total annihilation with $R$. convex only occurred after $2 \mathrm{~h}$ of exposure, while $I$. rufoniger still presented a $50 \%$ survival after $3 \mathrm{~h}$ of exposure to $50^{\circ} \mathrm{C}$. In a similar study, Holway et al. (2002) compared L. humile with five species native to California and also found that $L$. humile was less tolerant to higher temperatures (all killed after $1 \mathrm{~h}$ at $46^{\circ} \mathrm{C}$ ) than native species (others were only annihilated at temperatures above $50^{\circ} \mathrm{C}$ ).

On the other hand, Walters \& Mackay (2004) advised caution when interpreting such results as apparently ants can modulate behavior in response to environmental changes to avoid exposure to extreme conditions, and temperature should not be regarded isolated from other important abiotic factors. For instance, ant species living in deserts and other dry habitats can adapt by building their nests deeper into the soil, and diurnal species will usually forage in the morning and at nightfall (Hölldobler \& Wilson 1990). In a study of diurnal foraging in three tramp ant species from the Galapagos Islands, Meier (1994) found that foraging workers of $M$. floricola have a pattern of activity over the day, with peak activity during the day (from 06:00h 
to $18: 00 \mathrm{~h})$. From analyzing the foraging pattern for $M$. floricola presented by Meier (1994) on page 56, two significant decreases in the foraging at the peaks of activity can be perceived: between 11:00h and 13:00h and from 16:00h to 18:00h. Upon comparing Meier's graph with another illustration on page 56 of Meier (1994) presenting temperature variation over the day, it can be seen that the two reductions in foraging coincided with temperature variations: the first foraging reduction can be related with the peak temperatures of the day $30-32^{\circ} \mathrm{C}$ while the second reduction can be related with temperature dropping below $26^{\circ} \mathrm{C}$. Foraging ceased completely between 00:00h and 05:00h, period at which mean temperature remained around $22^{\circ} \mathrm{C}$. Interestingly, worker mortality was null in our experiments within the temperature range $18-30^{\circ} \mathrm{C}$, illustrating that $M$. floricola is well adapted to this temperature range. It should be emphasized, however, that even if a given ant species is tolerant to higher temperatures, this does not mean it will forage at such temperatures (Cerda et al. 1998).

Cerda et al. (1998) evaluated the thermal tolerance of a Spanish ant community of 11 species. One of their conclusions revealed a direct correlation between worker size and maximum critical temperature (i.e., a 10-min exposure to a given temperature in which $50 \%$ of worker wither died or were severely impaired): species with larger workers were more tolerant to higher temperatures. In our experiments, T. bicarinatum was the largest species and proved the least tolerant.

Francke et al. (1985) hypothesized that tolerance to different temperatures in ants can be influenced by worker age, ambient humidity, previous thermal regime, and colony diet, apart from colony location (Angilletta et al. 2007). As all three species were reared under the same room conditions and the tests employed only workers found outside the colonies - which are regarded as the oldest (Hölldobler \& Wilson 1990) - we think the observed differences between species directly reflect their intrinsic temperature tolerances.

Based on the results of this study we can state that workers of $M$. pharaonis are the most tolerant to higher temperatures among the tested species. Regarding temperatures below $25^{\circ} \mathrm{C}, T$. bicarinatum proved also the least tolerant. Other temperature studies with these species ought to evaluate their regulatory capacity at colony level, thus assessing general survival develop- 
ment of colony members, and the correlation of temperature with other environmental variables (like humidity), and the existing behavioral and physiological mechanisms to cope with extreme conditions.

\section{ACKNOWLEDGMENTS}

We would like to thank CAPES Institution for the financial support provided and to Eduardo Gonçalves Paterson Fox for kindly translating and revising the manuscript.

\section{REFERENCES}

Andersen, A.N. 1995. A classification of Australian ant communities, based on functional groups which parallel plant life-forms in relation to stress and disturbance. Journal of Biogeography 22: 15-29.

Andersen, A.N. 2000. A global ecology of rainforest ants: functional groups in relation to environmental stress and disturbance. In: Agosti, D., J.D. Majer, L.E. Alonso \& T.R. Schultz (eds). Ants: standard methods measuring and monitoring diversity. Smithsonian Institution Press, Washington: 25-34.

Angilletta, M.J., R.S. Wilson, A.C. Niehaus, M.W. Sears, C.A. Navas \& P.L. Ribeiro. 2007. Urban physiology: city ants possess high heat tolerance. PLoS ONE 2: e258.

Campos-Farinha, A.E.C., O.C. Bueno, M.C.G. Campos \& L.M. Kato. 2002. As formigas urbanas no Brasil: retrospecto. O Biológico 64: 129-133.

Cerda, X., J. Retana \& S. Cros. 1998. Critical thermal limits in Mediterranean ant species: trade-off between mortality risk and foraging performance. Functional Ecology 12: 45-55.

Chapman, R.F. 1998. The insects: structure and function. Cambridge University Press, Cambridge.

Francke, O.F., L.R. Potts \& J.C. Cokendolpher. 1985. Heat tolerances of four species of fire ants (Hymenoptera: Formicidae: Solenopsis). Southwestern Naturalist 30: 59-68.

Hebling-Beraldo, M.J.A. 1978. Tolerância às variações de temperatura, em operárias de saúvas. Revista Brasileira de Biologia 38: 195-199.

Hölldobler, B. \& E.O. Wilson. 1990. The ants. Harvard University Press, Cambridge.

Holway, D.A., A.V.Suarez \& T.J. Case. 2002. Role of abiotic factors in governing susceptibility to invasion: A test with Argentine ants. Ecology 83: 1610-1619.

Klotz, J., L. Hansen, R. Pospischil \& M. Rust. 2008. Urban ants of North America and Europe: identification, biology, and management. Cornell University Press, Ithaca.

Linksvayer, T.A. \& M.A. Janssen. 2008. Traits underlying the capacity of ant colonies to adapt to disturbance and stress regimes. Systems Research and Behavioral Science 26: 315-329. 
Meier, R.E. 1994. Coexisting patterns and foraging behavior of introduced and native ants (Hymenoptera, Formicidae) in the Galapagos Islands (Ecuador). In: Williams, D.F. (ed). Exotic ants: Biology, impact and control of introduced species. Wetsview Press, San Francisco: 44-62.

Passera, L. 1994. Characteristic of tramp species. In: Williams D.F. (ed). Exotic ants: Biology, impact and control of introduced species. Wetsview Press, San Francisco: 23-43.

Vega, S.J.V. \& M.K. Rust. 2001. The Argentine ant - A significant invasive species in agricultural, urban and natural environments. Sociobiology 37: 3-25.

Walters, A.C. \& D.A. Mackay. 2004. Comparisons of upper thermal tolerances between the invasive Argentine ant (Hymenoptera: Formicidae) and two native Australian ant species. Annals of the Entomological Society of America 97: 971-975.

Wetterer, J.K. 2008. Worldwide spread of the longhorn crazy ant, Paratrechina longicornis (Hymenoptera: Formicidae). Myrmecological News 11: 137-149.

Wetterer, J.K. 2009a. Worldwide spread of the ghost ant, Tapinoma melanocephalum (Hymenoptera: Formicidae). Myrmecological News 12: 23-33.

Wetterer, J.K. 2009b. Worldwide spread of the destroyer ant, Monomorium destructor (Hymenoptera: Formicidae). Myrmecological News 12: 97-108.

Wetterer, J.K. 2009c. Worldwide spread of the Argentine ant, Linepithema humile (Hymenoptera: Formicidae). Myrmecological News 12: 187-194.

Wetterer, J.K. 2009d. Worldwide spread of the Penny ant, Tetramorium bicarinatum (Hymenoptera: Formicidae). Sociobiology 54: 811-830.

Wetterer, J.K. 2010a. Worldwide spread of the flower ant, Monomorium floricola (Hymenoptera: Formicidae). Myrmecological News 13: 19-27.

Wetterer, J.K. 2010b. Worldwide spread of the pharaoh ant, Monomorium pharaonis (Hymenoptera: Formicidae). Myrmecological News 13: 115-129.

Xu, Y.J., Y.Y. Lu, Z.P. Pan, L. Zeng \& G. Liang. 2009. Heat tolerance of the red imported fire ant, Solenopsis invicta (Hymenoptera: Formicidae) in mainland China. Sociobiology 54: 115-126.

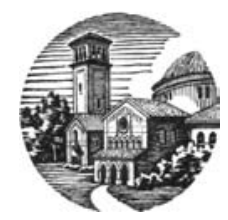


